\title{
A ENFERMAGEM DIANTE DA VIOLÊNCIA CONTRA A MULHER: UMA REFLEXÃO SOBRE OS DESCONHECIMENTOS DO PROFISSIONAL
}

\begin{abstract}
Nursing in front of violence against women: a reflection of professional discounts
\end{abstract}
\author{
Steffani Aparecida dos Santos Fernandes ${ }^{1}$
}

RESUMO: A violência de gênero ou violência doméstica contra a mulher tem atingido números assustadores em todo o país. Desde a vitória da biofarmacêutica Maria da Penha que levou o Estado a réu da corte interamericana devido à impunidade contra o seu caso após sofrer duas tentativas de homicídio, infelizmente o número de casos de feminicídio tem-se tornado cada dia maiores, e, em contrapartida, as ações legais e de promoção e prevenção não têm mostrado eficácia no combate a este subtipo de violência, de forma a alarmar a necessidade de revisão sobre o porquê do pequeno número de ações preventivas por parte da saúde e da não exigência das instituições sobre a notificação compulsória, que é obrigatória a todo profissional de saúde que se depare com casos suspeitos ou confirmados de violência interpessoal.

Palavras-chave: Mulheres. Violência de Gênero. Notificação.

ABSTRACT: Gender-based violence or domestic violence against women has scary targets across the country. Since the victory over biopharmaceuticals, the process of increasing violence against women and violence against domestic violence has been faced by all. From then on, the fight against violence and the fight against death is not necessary for the fight against violence and the prevention of the disease. On compulsory notification, which is mandatory for any health professional who comes across suspected or confirmed cases of interpersonal violence.

Keywords: Women. Gender-based violence. Notification.

\footnotetext{
${ }^{1}$ Graduanda em Enfermagem pelo Centro Universitário Presidente Tancredo de Almeida NevesUniptan.E-mail: teteferrari.sf@gmail.com.
} 


\section{INTRODUÇÃO:}

Atualmente, conforme a ONU, uma a cada três mulheres já sofreu algum tipo de abuso ou violência, vinda de membros da própria família ou vinda do ex-parceiro ou ainda do atual. Essa situação hoje é vista como caso de saúde pública, devido ao grande número de casos desde a criação da Lei Federal Ir.340/2006 de Combate à Violência Doméstica e Familiar, e que recebeu o nome popular de Lei Maria da Penha, homenageando a história e luta de Maria da Penha Maia Fernandes, que levou quase 20 anos para conseguir a justiça da punição e condenação do seu agressor, que na época era seu marido. Em 1983, enquanto dormia, ela recebeu um tiro do seu próprio marido, vindo a ficar paraplégica e ao voltar para casa foi vítima de inúmeras agressões, e uma outra tentativa de homicídio, dessa vez por eletrocução, também executada pelo seu marido. Após essa nova tentativa, Maria da Penha procurou auxílio da Justiça, vindo a deixar sua casa, com suas filhas (ARAGÃO, et al, 2013; PAIXÃO, 2014).

Na Justiça, o processo seguiu no Comitê Latino-Americano de Defesa dos Direitos da Mulher (CLADEM) e no Centro pela Justiça pelo Direito Internacional (CEJIL) a denúncia foi então formalizada junto à Maria da Penha à Comissão Interamericana de Direitos Humanos da Organização dos Estados Americanos e com essa iniciativa começou um grande debate e uma grande luta, onde várias ONG's lutaram para conseguir repercutir o caso às autoridades de forma que fossem revistas as punições e leis existentes na época (SOUZA, BARACHO, 2015).

Após um grande período, onde a proposta foi levada ao Congresso Nacional, com a intenção de atuar na coibição de casos de violência contra as mulheres, a lei foi sancionada no ano de 2006, quase nove anos depois da segunda tentativa de homicídio, onde na época exmarido de Maria Da Penha foi condenado a oito anos de prisão. Ao se tornar caso de saúde pública, o profissional de saúde, sobretudo o de enfermagem pelo primeiro e maior contato com o paciente, torna-se um grande aliado na identificação de casos em que haja violência doméstica, de forma a contribuir com a justiça. Porém, a realidade não é essa, estando numa sociedade claramente patriarcal, onde ainda impera a cultura machista, juntamente com a omissão e submissão de mulheres, que geralmente são vítimas de seus parceiros há anos ou 
até décadas, onde já não vê esperanças de uma vida diferente. O profissional de saúde tem como dever o preenchimento das notificações compulsórias, da comunicação de novas doenças e agravos, estando entre a lista, a violência. Com a obrigatoriedade da notificação desse tipo de agravo (violência), torna-se possível investigar e abordar qual o perfil deste tipo de violência, a fim de que haja a possibilidade da criação de instrumentos que promovam a saúde e a prevenção de novos casos, assim como a possibilidade de um maior controle por parte epidemiológica. Apesar de todo avanço na coibição dos casos, a notificação compulsória de violência contra a mulher ainda é pouco realizada, vindo a ser ainda um tema tabu, onde o profissional possui dificuldades na execução da identificação, da forma de abordagem a paciente ou ainda é preso a receios sociais e pessoais. (SOUZA, BARACHO, 2015)

A violência de gênero atinge mulheres de todas as idades, de todas as classes sócias e de todas as etnias. Não é um assunto recente, visto que existe em todas as sociedades desde os tempos primórdios, graças à cultura da necessidade da dominação do mais forte para com o mais fraco, do homem para com a mulher. Esta é uma forma de violar os direitos da mulher enquanto cidadã. A violência não acontece apenas em ambiente doméstico, ela pode acontecer em diversos ambientes, e a criação da Lei Maria da Penha foi importante para tipificar e definir quais são as formas de violência que podem ocorrer à mulher, com vistas a combatê-la de forma mais precisa. (SOUZA, BARACHO, 2015)

A importância da discussão e do estudo sobre a violência de gênero dentro do nosso sistema de saúde é de grande relevância, devido ao grande espaço que o tema tem alcançado na mídia, mas que parece ser um assunto distante dos debates na saúde pública. Para a elaboração deste estudo qualitativo foram revisados artigos para a construção de uma revisão crítica/narrativa, tendo como justificativa a necessidade de se analisar o contexto da violência doméstica no âmbito da saúde pública e refletir sobre o quão preparado os profissionais de enfermagem estão diante deste tema. Os dados foram coletados de março a setembro de 2018, sendo usados como descritores "violência de gênero", "mulheres", "violência de gênero", "notificação", utilizando-se da base de dados Scientific Eletronic Library Online (SciELO).

\section{Definições e aspectos da violência}

A violência é compreendida como fatores e ações que contribuam de forma prejudicial à vítima, causando-lhe opressão, danos psicológicos, danos físicos ou morte, necessitando de várias ações para profilaxia e até tratamento. Há vários tipos de violência, entre eles, a violência de gênero, que tem aumentado nos últimos anos e vêm ganhando 
números aterrorizantes na mídia e nas estatísticas, vindo o feminicídio e a violência contra a mulher a se tornar um caso de saúde pública:

De acordo com Paixão (2014, p. 725)

[...] A violência tem provocado forte impacto na morbidade e na mortalidade da população e é considerada um problema de saúde pública, pelo elevado número de vítimas que atinge e pelos impactos sociais, econômicos e pessoais que provocam, situando-se entre as principais causas de morte na faixa etária de is a 44 anos.

A Estratégia Saúde da Família (ESF) representa uma reorganização da Atenção Primária do país, de forma a expandir, reorganizar e consolidar o atendimento à demanda conforme os princípios do Sistema Único de Saúde (SUS). Ela é composta por uma equipe multiprofissional afim de atender as maiores necessidades da população, de acordo com sua atribuição específica ou comum: médico, enfermeiro, técnico de enfermagem, psicólogo, nutricionista, além dos agentes comunitários da saúde, que formam o vínculo dentro e fora da instituição da ESF (SIGNORELLI, AUAD, PEREIRA, 2013).

A atenção à saúde é buscada a fim de garantir o direito à universalidade, à integralidade, e a igualdade, cabendo a cada profissional acompanhar e avaliar sistematicamente todas as ações realizadas, para readequar o processo do trabalho de toda equipe. Com este processo proposto pelo SUS, a família passou a ser alvo de atenção, no ambiente em que ela vive, para compreender-se de forma ampliada, o processo saúde-doença (SIGNORELLI, AUAD, PEREIRA 2013).

A população vê a ESF como a primeira opção a encontrar seu direito à saúde, desta forma, mulheres vítimas de algum tipo de violência procuram o serviço, seja para solicitar tratamento em lesões ou até mesmo sintomas, que são percebidos pelo profissional de saúde. No momento em que este a atende, porém ainda sim esta procura mostra-se pouco resolutiva, visto que a tendência é de que haja negligência por parte da própria vítima ou até mesmo do profissional. Existe toda uma problemática que envolve a sociedade desde o seu princípio, por ser uma sociedade patriarcal, e que sempre impôs uma relação de desigualdade entre homens e mulheres. Toda mulher se vê desqualificada sob o ponto de vista social, fragilizada, aprendendo desde sua infância a enxergar-se submissa aos homens, devendo-lhes obediência absoluta, o que perdura até os dias de hoje. Apesar da ESF ter bastante contato com casos de violência, há muitos casos que obrigam o profissional a manter-se calado, omisso, inclusive à pedido da paciente (SIGNORELLI; AUAD; PEREIRA, 2013).

É preciso compreender que a violência não é apenas física, ela está "camuflada" dentro de atos mais sutis, e esses fatores complicam o sucesso do combate a ela. Há o abuso 
sexual, psicológico, financeiro, material, o gaslightining, e as dependências financeira e emocional, e esses múltiplos fatores que desencadeiam a violência física, devem ser trabalhados junto à vítima, o que não é tão simples. $O$ abuso psicológico muitas vezes não é visto como um tipo de violência, e ele acontece nas formas de manipulação, chantagem, ou "aproveitamento" das crises que as vítimas possam vir a ter. O parceiro ter total controle sobre as finanças e bens da vítima, bem como a privar de usufruir dos frutos de seu trabalho configura- se em violência financeira e material. O gaslightining acontece quando o parceiro cria situações em que põe a vítima como uma pessoa mentirosa, paranoica e a faz acreditar que está "louca", ou que está exagerando em sua reação (PAIXÃO, 2014).

Ainda dentro da violência, existem as dependências financeiras, onde por exemplo, a vítima possui muitos filhos e nunca trabalhou, ou o parceiro não a deixa trabalhar, além de não dá-la autonomia para buscar sua independência, o que a faz aceitar permanecer no abuso, por medo de não conseguir sustentar a si e a seus filhos e a emocional, que é a mais complexa de ser trabalhada, pois é uma questão psicológica, onde a vítima não tem total clareza do que se passa, vindo a achar que o que acontece é normal, ou que ela mereça, ou que não conseguiria viver outro relacionamento e é preciso que haja um tratamento psicológico para o empoderamento desta. $\mathrm{O}$ abuso sexual também pode ocorrer, mesmo quando com o próprio parceiro sexual, quando o ato ocorre sem consentimento ou sob pressão psicológica, ameaças ou chantagens feitas pelo abusador (SANTANA, et al., 2014).

A violência de gênero é cíclica, no qual ocorre o momento da agressão, seguida da "lua de mel" (momento no qual o agressor diz-se arrependido, vindo a ganhar novamente a confiança da parceira) que é a fase em que a vítima acredita que o abusador não voltará a agredi-la, e a fase de tensão, onde o agressor oprime a vítima, que aguarda o próximo episódio de violência, então passa a calcular o que faz, acreditando que isso evitará qualquer explosão do agressor, o que é inútil, pois a volta do ciclo é inevitável (SILVA, et al, 2015).

Esse fenômeno social não é algo recente, ele sempre existiu e há décadas atrás era considerado algo natural, visto que a mulher sempre foi vista como um ser inferior ao homem, e o machismo e sexismo sempre fizeram parte da sociedade, o que dificulta a aderência da vítima à denúncia, ou o apoio por parte da sociedade, que ainda trata a violência contra a mulher como um tabu, ou como algo que não deve ser discutido graças ao ditado popular 'em briga de marido e mulher ninguém mete a colher ', o que é interpretado de forma bastante equivocada. Os casos de agressões têm tomado proporções epidêmicas, devido à alta das taxas e o grau das agressões, o que impacta de forma bastante negativa a 
vida pessoal e social das vítimas, que sentem isoladas diante da hierarquia, da falta de autonomia, dos conflitos e dos desejos narcisistas predominantemente do parceiro. Hoje existe um forte apelo público ao combate e denúncia dos casos de violência doméstica, através de campanhas de conscientização (SILVA, et al, 2015).

O feminicídio se trata de um crime hediondo e tem como agravantes quando acontece em situações de vulnerabilidade e essas situações de vulnerabilidade muitas vezes são perceptíveis quando a vítima procura o serviço de saúde, principalmente a atenção primária, sendo o enfermeiro o primeiro profissional a entrar em contato com ela, e a poder ajudá-la e realizar a notificação compulsória dos casos, o que não depende apenas do profissional ou da vítima. Para isto, necessita-se de uma percepção aguçada, pois muitas vezes, a vítima tende a omitir o que de fato aconteceu, por medo. Durante a investigação de enfermagem é possível identificar diante do histórico da paciente fatores que possam indicar vulnerabilidade diante deste fenômeno e para isto, é preciso ouvir a paciente sem julgamentos, sempre visando o cuidado holístico, imparcial e ético, tendo em vista que além das lesões físicas, há o maceramento emocional, o que leva a vítima a uma enorme fragilidade diante das circunstâncias (PAIXÃO, 20I4; SANTANA, et al, 2017).

\section{O preconceito de gênero: da história até os dias atuais e os desconhecimentos do profissional de saúde}

O estereótipo que envolve a mulher não é um problema atual, ele vem desde a PréHistória, onde era preciso força física nas caçadas, função exclusiva do homem. Até os dias de hoje a mulher se vê cercada de preconceitos sociais, os quais a põe no papel de ser frágile incapaz de garantir sua própria sobrevivência. $O$ trabalho digno, nas ruas e que mantém a sociedade é apenas do homem, enquanto o trabalho submisso, "escondido" e doméstico é digno da mulher (SILVA, et al, 2015).

Por décadas (e até hoje e alguns países) era considerado direito do homem a punição física e pejorativa de sua esposa em caso de desobediência, e mesmo com tantos direitos conquistados pelas mulheres ao longo da história, como o direito ao voto, ao trabalho remunerado, ao divórcio, à educação e a criação de programas que garantem o direito à saúde feminina -como o PAISM- ainda hoje a mulher é vista como inferior e desigual (SILVA, et al, 2015).

Quando submetida à violência intrafamiliar e doméstica, a Atenção primária em ESF's, UBS's e Urgência e Emergência são os primeiros serviços procurados pela mulher, o 
que faz com que a Enfermagem esteja em primeiro momento, obtendo contato com a situação e sendo capaz de intervir na assistência física e psicológica, porém a realidade está distante de ser totalmente assim, devido a omissão por parte da vítima, do profissional e até mesmo do preconceito que a sociedade impõe (PAIX ̃̃O, 2014).

$\mathrm{O}$ enfermeiro na ESF atua em estratégias que visam a redução e o combate de reincidentes, porém os casos são bastante subnotificados a pedido da própria mulher, que depende do parceiro financeiramente muitas vezes. As vítimas em potencial são claramente identificadas segundo o contexto em que vivem na comunidade e são oferecidos o sigilo profissional e o suporte da instituição, porém mesmo com isso, há mulheres que não mais procuram ou até abandonam o serviço (PAIXÃO, 20I4).

$\mathrm{Na}$ prática ainda não é possível a assistência holística dessas vítimas, porque o serviço de saúde não é preparado para atender e notificar casos de violência e o profissional não se vê seguro a atuar com poucos recursos que sejam efetivos apesar da capacidade que se tem de se criar grupos de apoio, meios para interferir e intervir nos casos desde a chegada da mulher até sua denúncia formal junto à justiça, o que requer tempo e dedicação não só da enfermagem, mas de toda equipe multiprofissional (PAIXÃO, 2014).

A equipe tende a julgar a situação como um problema que tenha de ser resolvido por via jurídica ou via policial, mas o acolhimento e a orientação dada à mulher são capazes de ser um passo inicial importante para que ela não se veja mais como isolada e como invisível aos olhos da sociedade, e que ela tenha consciência de que não é um problema só dela. A partir daí a mulher pode entender o contexto complexo em que ela está inserida, para ela própria compreender que é capaz de mudar sua situação, superando julgamentos e preconceitos que inevitavelmente aparecerão conforme suas decisões (PAIXÃO, 20I4).

Para a criação de um trabalho de promoção e prevenção tão efetivo, a equipe multidisciplinar precisa ser esclarecida e preparada para a situação, desligada de estereótipos e preconceitos que cresceram vendo a sociedade implantar como normal, e retirar da mente o famoso "em briga de marido e mulher, ninguém mete a colher" (ditado popular), pois mesmo frequente, a violência ainda é pouco identificada, percebida e notificada nas instituições de saúde (WAISELFISZ, 2015).

A notificação é um instrumento do Ministério da Saúde, de porte obrigatório, feito pelo profissional da saúde, para documentação nos casos de suspeita ou ocorrência de doenças e de seus agravantes, incluindo a violência, porém a subnotificação acontece em demasia, por medo do profissional em trazer o problema para si, pelo despreparo técnico do 
profissional, pelo desconhecimento teórico-científico, por ameaças sofridas pelo autor da violência, por falta de estrutura, pela falta de segurança, pelo medo da desassistência ou pelo fato de considera a notificação uma quebra de sigilo e o rompimento da ética profissional, o que deverão ser abordados no preparo do profissional(PAIXÃO, 2014).

A finalidade da notificação é o controle e o combate, assim como a criação de um canal de comunicação com órgãos superiores realizando seu processo de encaminhamento e de proteção à vítima de forma competente e eficaz. A notificação compulsória da violência inclui garantir o direito a integridade física e mental, digna de qualquer cidadão. A notificação é encaminhada ao Serviço Social, que deverá encaminhá-la ao órgão competente, a depender do caso notificado. O profissional poderá orientar e incentivar a vítima a realizar sua denúncia formal nas Delegacias da Mulher (CROVATO, 2017).

Infelizmente a rede de saúde ainda está pouco interligada no combate à violência através da notificação compulsória-obrigatória, a qualidade do sistema ainda é falha e o profissional deve ter a consciência de que notificar não é denunciar, portanto deve-se sim notificar mesmo uma simples suspeita, para que órgãos competentes investiguem a situação e encaminhem para a intervenção necessária para cada caso identificado e notificado (SANTANA, et al, 2014).

Para intervir junto ao problema da subnotificação, a instituição deve organizar-se a fim de se comprometer com o combate à violência, preparando a equipe para atuar de forma adequada, esclarecendo e preparando-os para os casos que poderão ser identificados, para que não haja dúvidas ou receios por parte do profissional (RIBEIRO, 2013).

A ausência das notificações limita de forma grandiosa o combate à violência e seu agravo, no âmbito da saúde, da vítima e da justiça. O que não é notificado, não ocorreu, portanto não é investigado e combatido. A notificação é feita da mesma forma que doenças e agravos classificados como de notificação compulsória, viabilizando informações fidedignas, já que o sistema carece de políticas que sirvam de via para a prevenção de casos (RIBEIRO, 2013).

\section{Subnotificação e desconhecimentos do profissional}

A notificação compulsória é de caráter obrigatório a todo profissional de saúde que preste assistência ao paciente ou ao responsável pelo serviço assistência prestado e deverá ser realizada sempre que houver casos de suspeita ou confirmação de eventos, doenças ou agravos de saúde (GARBIN, et al, 20I4). 
O profissional de saúde tem como arma de combate às formas de violência a notificação compulsória de doenças e agravos, após ter ocorrido a sua nova formulação em 201 incluindo a violência contra a mulher como um dos tipos de agravo à saúde que devem ser notificados. A violência doméstica é um reflexo de como a sociedade vê e trata a mulher de maneira desigual, vindo a interferir de forma grandemente negativa em como a vítima se encara e encara o que vive, fazendo com que ela mesma omita ao profissional, tenha medo de exposição ou de vingança do agressor (GARBIN, et al, 2014).

O preenchimento da notificação traz a possibilidade de serem elaborados meios de combate através de informações mais fidedignas que ali estarão registradas. Graças ao aumento do número de agressões houve a criação de projetos e de programas que se voltaram ao estudo deste tipo de violência, porém não há cobrança por parte do governo e autoridades, nem há uma rede interligada com a saúde pública e as autoridades, por exemplo, policiais. A quebra de sigilo profissional também se torna um entrave na notificação, porém quando é identificado um risco de vida iminente a vítima, torna-se imprescindível que o profissional entre em ação junto aos órgãos competentes, seja o serviço social ou o programa da unidade de saúde (GARBIN, et al, 20I4).

Todo profissional de saúde possui seu Código de Ética baseado na responsabilidade deôntica, para a promoção da saúde. Ao subnotificar, o profissional expõe ao Código penal e de ética, por inobservar as obrigações a ele estabelecidas enquanto exercer sua profissão. A notificação é um instrumento eficaz para a epidemiologia e para as políticas públicas e deixar de fazê-lo é um erro grave do profissional, por estar atuando de forma antiética ao tornar subnotificado casos de violência, seja por medo de posteriores ameaças por parte do agressor, seja pelo desconhecimento de que notificar não é denunciar (GARBIN, et al, 2014).

Com a desarticulação da rede do combate à violência, e das autoridades competentes, tornam-se evidentes problemas das instituições em tornar a notificação efetiva, desde a falta de fiscalização, falta de respaldo pela mesma, que gera no profissional um sentimento de insegurança, pela complexidade do tema, despreparo para lidar com a notificação, entre outros (PAIXÃO, 2014).

Mesmo impondo obrigatoriedade de notificação, o país não se dispõe a atuar no preparo desses profissionais de saúde, o que defasa todo o sistema, e impossibilita a continuidade do combate. O seu cumprimento implica diretamente na possibilidade do sistema em criar e dar prioridade as políticas públicas de vigilância e de assistência afim de 
diminuir os casos, melhorar a assistência, além de diminuir os gastos da saúde com casos desse tipo (CROVATO, 2017).

Para superar todo o receio e a resistência do profissional, é de suma importância que haja educação continuada de forma que amplie a visão da equipe, para que não vejam a violência como apenas ameaça a integridade física, mas que vejam todo o processo que acontece por trás dos hematomas e que vejam o quanto é necessária a atuação destes na valorização da vida, além de esclarecer todos os aspectos éticos-legais e respaldos que eles terão após sua notificação, afim de gerar a segurança necessária para a adesão ao sistema (RIBEIRO, 2013).

\section{Conclusão}

Apesar de todos os avanços no combate a violência doméstica, ainda é preciso que haja programas que incentivem o profissional de saúde a notificar os casos que atendem, em nome da promoção e prevenção de saúde, assim como é preciso investir na educação continuada desses profissionais de forma a esclarecer a complexidade do tabu da violência, e formar profissionais preparados a lidar com esse tipo de ocorrência, seguros para atuar de forma a visar a prevenção de agravos maiores a paciente e para que haja melhora no atendimento, o profissional precisa estar seguro de que será respaldado e amparado pela instituição ao notificar e comunicar aos órgãos pertinentes.

\section{REFERÊNCIAS}

ARAGAO, Ailton de Souza et al. Abordagem dos casos de violência à criança pela enfermagem na atenção básica. Rev. Latino-Am. Enfermagem, Ribeirão Preto, v. 2I, n. spe, p. I72-179, 2013.

CROVATO, Cristina Aparecida dos Santos. A notificação compulsória da violência e seus desafios no processo de trabalho dos profissionais de saúde das unidades básicas de saúde da família em Uberlândia/MG. 2017. 97 f. Dissertação (Mestrado em Saúde Ambiental e Saúde do Trabalhador) - Universidade Federal de Uberlândia, Uberlândia, 2017.

GARBIN, Cléa Adas Saliba et al. Desafıos do profıssional de saúde na notificação da violência: obrigatoriedade, efetivação e encaminhamento. Ciênc. saúde coletiva, Rio de Janeiro, v. 20, n. 6, p. 1879-189o, 2015.

PAIXÃO, Leonardo Augusto Bacellar De Novaes. Assistência de enfermagem à mulher vítima de violência. 2014. 34 f. Monografia (Bacharelado em Enfermagem) Universidade de Brasília, Ceilândia-DF, 2014. 
RIBEIRO, Dominique de Paula. Livro Violência contra a mulher-Aspectos Gerais e questões práticas da Lei no $11.340 / 2006$. Gazeta Jurídica, 2013.

SANTANA, Tawana Bárbara Lima de., et al. Violência Contra à Mulher: Uma perspectiva do Enfermeiro no enfrentamento junto as vítimas. Universidade Tiradentes., Alagoinhas-BA, 2017.

SIGNORELLI, Marcos Claudio; AUAD, Daniela; PEREIRA, Pedro Paulo Gomes. Violência doméstica contra mulheres e a atuação profissional na atenção primária à saúde: um estudo etnográfico em Matinhos, Paraná, Brasil. Cad. Saúde Pública, Rio de Janeiro, v. 29, n. 6, p. 1230-1240, Jun 2013

SILVA, Agnês Raquel Camisão et al. Discriminação contra a mulher - revisão integrativa da literatura. Revista da Associação Brasileira de Pesquisadores/as Negros/as (ABPN), [S.1.], v. 7, n. 15, p. 16I-174, fev. 2015.

SOUZA, Mércia Cardoso; BARACHO, Luiz Fernando. A lei maria da penha: égide, evolução e jurisprudência no brasil. Revista Eletrônica do Curso de Direito PUC Minas Serro, Belo Horizonte, n. II, p. 79-106, ago. 2015.

WAISELFISZ, Júlio Jacobo. Mapa da Violência 20I5: Homicídio de mulheres no Brasil. Flacso Brasil., Brasília-DF, 2015. 